\title{
Sikap Perempuan dalam Kumpulan Cerpen pada karya Ratna Indraswari Ibrahim dengan Kajian Feminisme dan Implementasinya dalam Pembelajaran sastra di SMA
}

\author{
Eka Yulianti ${ }^{1}$, Sugerman ${ }^{2}$, Lili Suryaningsih ${ }^{3}$ \\ 1,2,3 Program studi Pendidikan Bahasa dan Sastra Indonesia, STKIP Yapis Dompu \\ E-mail corresponding: eka24547@gmail.com
}

Article History: Received: 2021-07-22 || Revised: 2021-07-28 || Published: 2021-08-31

Sejarah Artikel : Diterima: 2021-07-22 || Direvisi: 2021-07-28 || Dipublikasi: 2021-08-31

\begin{abstract}
The attitude of women in literature can mean anything. The existence of a female figure in a literary work is not only a complement to a story but as a central figure in a literary work the objectives of this research are (1) Describe the intrinsic element in the collection of short stories by Ratna Indraswari Ibrahim with a study of feminisme (2) Describe the attitude of women collection of short stories by Ratna Indraswari Ibrahim study of feminisme (3) Describe implentasion of a collection of short stories by Ratna Indraswari Ibrahim as teaching materials for high school literature. This study used a qualitative descriptive methud. The objects examined in this study were the attitudes of women in a collection of short stories by Ratna Indraswari Ibrahim. The data sorce used in this study is secondary data, namely a collection of short stories by Ratna Indraswari Ibrahim. Data collection techniques, namely using documentati on, reading and taking notes the data analysis technique used was to collect data un the form of three short stories by Ratna Indraswari Ibrahim. Data reduction datapresentasion and conclusions. The result of this study indicate that I, the intrinsic elements of the three stories of Ratna Indraswari Ibrahim short stories are seen from the cohesion and story of friends.(2)study of feminism or women'sattitudes contained in a colecition of short stories by Ratna Indraswari Ibrahim (3) Implementation in the form of teaching materials, lesson plans and literary learning syllabus in SMA class XI.
\end{abstract}

Keywords: Women's, Feminisme, Iplementasion, taching materials in high school

\begin{abstract}
Abstrak
Sikap perempuan dalam karya sastra bisa berarti apa saja. Keberadaan sosok perempuan di dalam karya sastra tidak hanya sebagai pelengkap sebuah cerita melainkan sebagai tokoh sentral dari sebuah karya sastra. Tujuan Penelitian ini adalah (1) mendeskripsikan unsur intrinsik dalam kumpulan cerpen karya Ratna Indraswari Ibrahim, (2) mendeskripsikan sikap perempuan dalam kumpulan cerita pendek karya Ratna Indraswari Ibrahim dengan kajian feminisme, (3) Mendiskripsikan implementasi kumpulan cerita pendek karya Ratna Indraswari Ibrahim sebagai bahan ajar sastra di SMA. Penelitian ini menggunakan metode deskriptif kualitatif. Objek yang diteliti dalam penelitian ini adalah sikap perempuan yang ada pada kumpulan cerita pendek karya Ratna Indraswari Ibrahim. Sumber data yang digunakan penelitian ini adalah data sekunder yaitu kumpulan cerita pendek karya Ratna Indraswari Ibrahim. Teknik pengumpulan data, yakni menggunakan teknik dokumentasi, baca, dan catat. Teknik analisis data yang digunakan adalah mengumpulkan data berupa tiga cerpen Ratna Indraswari Ibrahim, reduksi data, penyajian data dan kesimpulan. Hasil penelitian ini menunjukkan bahwa (1) unsur intrinsik ketiga cerpen Ratna Indraswari dilihat dari kepaduan dan tema cerita. (2) kajian feminisme atau sikap permpuan yang terdapat dalam kumpulan cerpen karya Ratna Indraswari Ibrahim. (3) implementasinya dalam bentuk Bahan Ajar, RPP dan silabus pembelajaran sastra di SMA kelas XI.
\end{abstract}

Kata kunci: Cerpen, Sikap perempuan, Feminisme, Implementasi, Bahan ajar di SMA

\section{PENDAHULUAN}

Karya sastra merupakan suatu gambaran luar biasa yang terbentuk oleh khayalan kreatif dan produktif seorang pengarang. Senada dengan itu, (Waluyo 2002:68) mengatakan bahwa karya sastra adalah sebagai wujud nyata imajinasi kreatif sastrawan dengan proses yang berbeda antara pengarang yang satu dengan yang lain. Karya sastra selalu menyajikan keindahan tersendiri bagi setiap penikmatnya. Cerpen dapat dijadikan sebagai sarana pembelajaran sehingga dapat diambil 
manfaat dan pelajaran dalam kehidupan untuk menjadikan hidup lebih baik dan karya sastra secara umum kerap dipandang sebagai upaya merepresentasikan kenyataan oleh sebab itu sastra dikatakan sebagai imitasi atau peniruan kenyataan.

Kumpulan cerpen karya Ratna Indraswari Ibrahim sangat menarik untuk dibaca. Ratna Indraswari Ibrahim merupakan seorang sastrawan besar dengan segala kelebihan dan keterbatasanya. Keunikan RII sebagai sastrawan adalah mampu mencipta karya sastra hampir 500 karya sastra baik berupa novel, novelete, dan cerpen meski kondisi fisiknya terbatas, meski dirinya seorang difabel. Kedifabelannya tidak mengurangi dirinya untuk selalu berbuat humanis, berjuang, dan melawan segala bentuk ketidakadilan. Kumpulan cerpen karya Ratna Indraswari Ibrahim, peneliti menganalisis tiga cerpen yaitu "Sumi dan Gambarnya", "Rambutnya Juminten" dan "Bunga", ketiga cerpen tersebut sangat menarik untuk di teliti karena ketiga cerpen menceritakan ketidakadilan gender yang dirasakan perempuan dengan kajian feminisme. Penelitian ini diharapkan juga mampu menjadi bahan ajar alternatif dalam mata pelajaran Bahasa Indonesia di SMA. Salah satu tujuan pembelajaran sastra adalah agar peserta didik memiliki dan memanfaatkan karya sastra untuk memerluas wawasan, memperhalus budi pekerti serta meningkatkan pengetahuan kemampuan mengapresiasi dan menikmati karya sastra (Sufanti, 2010:23).

Penelitian tentang kajian feminisme sastra telah dilakukan oleh pertama Afriyendi Gusti mahasiswa Universitas Andalas pada tahun 2004. Dengan judul "Sikap perempuan dalam kumpulan cerpen Sumi dan Gambarnya"karya Ratna Indraswari Ibrahim dengan kajian feminisme. Hasil penelitian tersebut mendeskripsikan kajian feminisme dalam kumpulan cerpen karya Ratna Indraswari Ibrahim. Peneliti kedua Anggun Putrihana mahasiswa Universitas Muhamadiyah Purwokerto pada tahun 2014, Berdasarkan uraian di atas maka, peneliti tertarik dengan materi tentang sikap perempuan dalam kumpulan cerpen karya Ratna Indraswari Ibrahim kajian feminisme dan implementasinya dalam pembelajaran sastra di SMA.

\section{METODE PENELITIAN}

Jenis peneliian yang digunakan dalam penelitian ini adalah penelitian kepustakaan atau library research yakni penelitian yang dilakukan melalui mengumpulkan data atau karya tulis ilmiah yang bertujuan dengan objek penelitian atau pengumpulan data yang bersifat kepustakaan, atau telaah yang dilaksanakan untuk memecahkan suatu masalah terhadap bahan-bahan pustaka yang relevan. Metode deskriptif kualitatif. Sesuai dengan penjelasan mengenai penelitian kualitatif, penelitian ini bertujuan untuk mendeskripsikan sikap perempuan dalam kumpulan cerpen pada karya Ratna Indraswari Ibrahim kajian feminisme dan implementasinya dalam pembelajaran sastra di SMA, Kajian kepustakaan yakni kegiatan dalam mencari, mengumpulkan, dan mendapatkan data-data yang diperlukan dengan cara menelaah dan menganalisis, penelitian yang dimaksudkan untuk mengumpulkan informasi mengenai subyek penelitian dan perilaku subyek penelitian pada suatu periode tertentu. Secara umum penelitian deskriptif adalah untuk mengumpulkan informasi mangenai subjek penelitian yang berusaha untuk mendeskripsikan keadaan yang ada pada saat penelitian dilakukan.

Untuk memperoleh data dalam penelitian ini, penelitian menggunakan teknik dokumentasi, teknik baca dan teknik catat sebagai teknik penggumpulan data. Teknik dokumentasi ini digunakan melalui pengamatan data serta catatan yang berkaitan dengan dokumen- dokumen terdahulu seperti jurnal dan buku. Selain teknik itu, peneliti juga menggunakan teknik baca ini digunakan untuk mengatahui unsur intrinsik dan kajian feminisme dalam kumpulan cerpen karya Ratna Indraswari Ibrahim.kesal. Sedangkan teknik catat yaitu mencatat sejumlah kata atau kalimat yang terdapat pada kumpulan cerpen karya Ratna Indraswari Ibrahim. Setelah semuanya dicatat, kemudian melakukan analisis data yang berupa kesalahan berbahasa pada surat media daring serta menentukan hasil dari penelitian, data penelitian ini berupa kajian tentang unsur intrinsik ketiga cerpen karya Ratna Indrasawari Ibrahim yaitu cerpen "Sumi dan Gambarnya", Rambutnya Juminten" dan "Bunga" dengan kajian feminisme dan implementasinya dalam pembelajaran sastra di SMA. 
III. HASIL DAN PEMBAHASAN

a) Unsur Intriksik cerpen "Sumi dan Gambarnya"

\section{Tema}

Judul cerpen yang pertama dianalisis adalah cerpen yang berjudul "Sumi dan Gambarnya". Cerpen ini bertemakan pemberontakan yang dilakukan oleh Sumi. Terlihat pada kutipan sebagai berikut "Sumi ke kota, sebagai buruh pabrik. Diantara jam-jam kerja, dia merindukan keluarganya, bahkan Bejo yang kabarnya sudah menikah lagi dengan perempuan lain".

Berdasarkan kutipan di atas adalah merupakan bentuk pemberontakan.

\section{Alur/Plot}

Alur yang digunakan dalam cerpen ini adalah alur maju. Dengan tahapan sebagai berikut ini.

a) Masalah muncul

"Kehidupan Sumi dan suaminya, Bejo di sebuah desa. Keadaan sumi yang merasa tersiksa dengan keadaan rumah tangganya bersama Bejo".

b) Masalah memuncak

"Sumi ingin pergi ke kota, tetapi tidak diperbolehkan oleh Bejo. Sementara Bejo ingin menikah dengan perempuan lain yang tidak lain adalah tetangga di daerah rumah mereka. Pelukis telah menjual lukisan kepada kolektor asing".

Kutipan di atas menunjukan kekecewaan yang di rasakan Sumi karena pengianatan yang dilakukan oleh Bejo dan Pelukis.

c) Antiklimaks

"Sumi dilarang Pardi untuk membunuh Pelukis, ia lantas melamar Sumi agar mau menjadi istrinya". Tahap penyelesaian "Sumi menikah dengan Pardi".

Dari tahapan di atas bahwa alur cerpen "Sumi dan Gambarnya". Menggunakan alur Maju karena jalan ceritanya tidak terhubungan dengan masa lalu melainkan menceritakan kehidupan Sumi saat sekarang.

\section{Latar/ setting}

a) Latar Tempat

Latar tempat dalam cerpen ini diceritakan terjadi di empat tempat, yaitu toko, rumah mewah, kamar dan kos-kosan . Berikut beberapa kutipan yang menunjukan latar tempat dalam cerpen "Sumi dan Gambarnya".

"Dia memasang lukisan ditengah-tengah tokonya". (kutipan ke 1 ) (UICSDG/FL/2003 "Lukisan Sumi terpampang di rumah mewah sang kolektor". (kutipan ke 2) (UICSDG/FL/2003)

"Keduanya kini membiarkan dia terlempar di kamar sempit ini". (kutipan ke 3) (UICSDG/FL/2003)

"pulang ke rumah kontrakanya". (kutipan ke 4) (UICSDG/FL/2003)

b) Latar Waktu

Latar waktu dalam cerpen "Sumi dan Gambarnya" dapat dilihat dari kutipan berikut ini.

"Bejo mengatakan, sebaiknya dua atau tiga tahun lagi mereka punya anak, kalau Bejo sudah punya pekerjaan yang lebih bagus. Sumi sebetulnya igin membantah". UICSDG/FL/2003)

Terlihat pada kutipan di atas latar waktu menunjukan dua atau tiga tahun lagi.

c) Latar suasana

Latar suasana dari cerpen ini dapat dilihat dari kutipan berikut ini:

"Kamu tidak pernah mau belajar menjadi istri yang baik."kata bapaknya berang. Sumi gelagapan. Dia merasa salah tidak tahu apa yang bisa di ucapkan kepada bapaknya". UICSDG/FL/2003)

"dengan kacau dia pulang ke rumah kontakannya yang sedang sepi". (UICSDG/FL/2003)

Terlihat pada kutipan di atas suasana yang terjadi kemarahan yang diterima Sumi dari Bapaknya dan suasana tempat tinggal Sumi yang sedang sepi.

\section{Tokoh dan Penokohan}

"Saya akan binasakan mereka! Saya tidak bakal puas kalau tidak membinasakan Bejo dan pelukis itu," jerit Sumi sambil menangis". (UICSDG/FL/2003)

Kutipan di atas menunjukan bahwa Sumi adalah tokoh utama. Sumi memiliki sifat yang tegar, penurut dan pendendam. 
"di antara jam kerja, dia merindukan keluarganya, bahkan Bejo yang kabarnya sudah menikah lagi dengan perempuan lain".(kutipan 2) UICSDG/FL/2003)

Kutipan di atas menunjukan bahwa Bejo adalah tokoh antagonis. Bejo memiliki sifat kejam, tidak setia dan tidak bertanggung jawab

"Sumi tertegun. Bukankah pedagang itu pernah berjanji tak Bakal menjualnya, sekalipun gambarnya ditawar mahal". (kutipan 3) UICSDG/FL/2003)

Berdasarkan kutipan di atas Pelukis adalah tokoh tambahan dalam cerpen. Pelukis memiliki sifat materialistis, tidak menepati janji dan. Kasar.

"Yah, sekarang anda tahu, kan? Kami merawatnya dengan baik sekali sehingga gambar itu masih tersenyum bahagia".(kutipan 4) UICSDG/FL/2003)

Tokoh Kolektor sebagai tokoh tambahan kedua dalam cerpen, di ceritakan seseorang yang baik dan menepati janji .

"Juminten memberi nasehat, "kita cuma orang biasa. Tidak usah berfikir aneh-aneh. Lebih baik kau menikah saja dengan pardi". (UICSDG/FL/2003)

Tokoh Juminten sebagai tokoh tambahan ke tiga, Juminten adalah teman yang baik dan bijaksana. Hal ini dapat di lihat dari kutipan berikut ini.

"Bapak seharusnya tidak sekasar itu pada symbol kebagiaan kita!"(UICSDG/FL/2003)

Kutipan di atas menunjukan tokoh Mahasiswa adalah orang yang baik dan cinta seni. Hal ini dapat di lihat dari kutipan berikut ini.

\section{Sudut Pandang}

Sudut pandang yang digunakan dalam cerpen "Sumi dan Gambarnya" adalah sudut pandang orang ketiga, karena penulis menceritakan kisah perjuangan seorang wanita bernama Sumi yang ingin bebas dari siksaan suaminya Bejo dan ingin meraih kebahagiaan dan kebebasanya kembali.

\section{Amanat}

Amanat yang dapat di ambil dari cerpen "Sumi dan Gambarnya". Menjadi seorang perempuan tidaklah mudah, ketika kita hidup dalam lingkungan masyarakat yang masih menganut budaya patriarki. Perempuan harus berjuang melawan ketidakadilan yang di rasakannya.

\section{b) Sikap Perempuan dalam Cerita Pendek "Sumi dan Gambarnya" kajian feminisme}

"Kini dia istrinya Bejo, lelaki se-desanya. Sumi mencintai Suaminya. Ucapan suami adalah perintah bagi Sumi, yang diterimanya dengan lego-lilo." (SPDCSDG/FL/2003)

Kutipan 1 di atas menunjukkan bukti bahwa Sumi selalu menuruti perintah suaminya, Bejo. Dia tidak berani melawan perintah suaminya sekalipun dia tidak suka menuruti suatu perintah tertentu. Ketidakadilan gender berikutnya yang berhubungan dengan lingkungan keluarga yang diambil dari cerpen ini merupakan suatu permasalahan yang sering dialami oleh wanita, yaitu kekerasan dalam rumah tangga. Hal ini terdapat pada kutipan sebagai berikut. Sumi yang sedang dibicarakan, baru saja ditampar suaminya. Karena Sumi masih tentang keinginannya bercerita untuk bekerja di kota.

"Kalau saya dengar ucapanmu lagi, kalu tahu sendiri akibatnya!" Sumi tertunduk. Dia takut sekali dengan ucapan suaminya". (SPDCSDG/FL/2003)

"Kamu tidak pernah mau belajar jadi istri yang baik", kata bapaknya berang. Sumi gelagapan. Dia merasa salah. Dan tidak tahu apa yang bisa diucapkan pada bapaknya. Karena, dia begitu jenuh pada Bejo. Dan dia sendiri tidak bisa menerangkan, jelasnya bagaiman". (SPDCSDG/FL/2003)

Kutipan 2 di atas menunjukkan bukti bahwa Sumi disalahkan oleh bapaknya karena melaporkan perbuatan suaminya yang telah memperlakukan dia sesuka hati. Bukan dukungan yang diberikan oleh bapaknya, melainkan amarah yang diterimanya yang menambah masalah bagi hidupya.

\section{c) Sikap Perempuan dalam Cerita Pendek "Rambutnya Juminten" kajian feminisme}

"Saya tidak, akan mengijinkan kamu memotong rambut semodel Marni. Sebagai suami, saya 'kan tahu model apa yang pantas untukku! Kamu tidak usah ikut-ikut gaya orang lain". (SPDCRJ/FL/2002)

Feminisme dalam cerpen rambutnya Juminten diantaranya berupa pertama, perbedaan gender yang mendominsai peran suami dalam rumah tangga yang berupa penindasan terhadap perempuan. Kedua, pandangan masyarakat yang menitikberatkan perempuan yang mengakibatkan ketidakadilan gender, dan yang ketiga pandangan laki-laki terhadap feminisme. 


\section{d) Sikap Perempuan dalam Cerita Pendek "Bunga" kajian feminism}

Cerpen ke tiga "Bunga" Jika dilihat dari sikap perempuan tokoh Rubiyah dan Yu Didit adalah tokoh yang memiliki jiwa pejuang dan melawan deskriminasi dari keluarga ataupun masyarakat dengan menunjukan pencapaiannya dengan bisa bekerja di bidang domestik.

e) Implementasi Kumpulan Cerita Pendek karya Ratna Indraswari Ibrahim Sebagai Bahan Ajar Sastra di SMA.

Implementasi kumpulan cerita pendek karya Ratna Indraswari Ibrahim sebagai bahan ajar di SMA dapat dikategorikan menjadi 4 aspek, yaitu a) fungsi sastra. b) Fungsi pembelajaran c) Pemilihan bahan ajar yang relevan, dan d) Penerapan Kompetensi Inti dan Kompetensi Dasar. Kumpulan cerita pendek karya Ratna Indraswari Ibrahim ini cocok digunakan untuk bahan pembelajaran pendidikan SMA, Sesuai dengan KI-KD (Kompetensi Inti - Kompetensi Dasar) di SMA kelas XI

Kompetensi Dasar Mengindetifikasi nilai kehidupan yang terkandung dalam

$3.18 \quad$ kumpulan cerpen yang di baca.

Rahmanto (2004:27-33) menyatakan, dalam kesesuaian bahan ajar pembelajaran sastra, ada tiga hal aspek yang tidak boleh dilupakan dalam memilih bahan ajar sastra, yaitu aspek bahasa, aspek psikologi, dan latar belakang budaya, a)Ditinjau dari Sudut Bahasa Kumpulan cerita pendek karya Ratna Indrsawari Ibrahim dapat digunakan dalam pembelajaran sastra di SMA khususnya terhadap peserta didik kelas XI semester ganjil. Kumpulan cerpen ini dapat dijadikan bahan pengajaran sastra karena bahasa yang digunakan dapat dipahami pada tingkatan SMA. b) Ditinjau dari Segi Kematangan Jiwa (psikologi), Ditinjau dari Segi Kematangan Jiwa (Psikologi) Kumpulan cerita pendek karya Ratna Indraswari Ibrahim dapat digunakan dalam pembelajaran sastra di SMA khususnya peserta didik. Hal tersebut sesuai dengan tahap perkembangan psikologis anak pada usia 13 sampai 17 tahun. D) Ditinjau dari sudut latar belakang budaya. Ditinjau dari Sudut Latar Belakang Budaya Kumpulan cerita pendek karya Ratna Indrasawari Ibrahim dapat digunakan dalam pembelajaran sastra di SMA khususnya peserta didik. Kumpulan cerita pendek tersebut memiliki latar belakang budaya yang sama yaitu masih menganut budaya patriarki.

\section{SIMPULAN DAN SARAN}

\section{A. Simpulan}

Berdasarkan hasil penelitian skripsi ini adalah a) menganalisis unsur intrinsik berupa tema, alur, penokohan, latar, sudut pandang dan amanat dalam kumpulan cerpen karya Ratna Indraswari Ibrahim yaitu tiga cerpen, "Sumi dan Gambarnya", Rambutnya Juminten" dan "Bunga". b) menganalisis kajian feminisme yang terdapat dalam kumpulan cerpen karya Ratna Indraswari Ibrahim, c) menganalisis tiga cerpen karya Ratna Indraswari Ibrahim dan impelementasinya dalam pembelajaran sastra di SMA di kelas XI semester satu dalam bentuk Bahan Ajar, RPP, dan Silabus.

\section{B. Saran}

Bagi penelitian lainya disarankan agar hasil penelitian ini dapat dimanfaatkan sebagai bahan acuan dalam melakukan penelitian yang lebih baik mengenai karya sastra pada umumnya. Dengan adanya penelitian tentang hasil karya sastra pembaca dapat mengetahui unsur intrinsik maupun kajian feminisme yang terkandung dalam kumpulan cerpen karya Ratna Indraswari Ibrahim. Bagi tenaga pendidik khususnya yang mnegajar mata pelajaran bahasa Indonesia disarankan aagar hasil penelitian ini dimanfaatkan bahan acuan dalam mendidik.

\section{DAFTAR RUJUKAN}

Aminudin, 2002. Pengantar Apresiasi Karya Sastra. Bandung: Sinar Baru.

Anggun Putrihana. 2014. "Citra Perempuan dalam Kumpulan cerpen Ayahmu Bulan, Engkau Matahari" karya Lily Yulianti Farid studi feminisme.

Arimbi. H dan R Valentina. 2004.Feminisme Vs Neoliberalisme. Jakarta: Debt Watch Indonesia.

Atar Semi. 1993. Metode Penelitian Sastra. Bandung: Angkasa. 
Beauvoir, De Simone, The Second Sex. Kehidupan Perempuan, diterjemahkan oleh Toni B. Febriantono, Dkk, Pustaka Prometea, Jakarta, 2003.

Bhasin dan Khan. 1995. Persoalan Pokok Mengenai Feminisme dan Relevansinya. Jakarta: Gramedia Pustaka Utama

Djajanegara, Soenarjati. 2000. Kritik Sastra Feminis Sebuah Pengantar. Jakarta: Gramedia Pustaka Utama.

Endraswara, Suwardi. 2003. Metodologi Penelitian Sastra.Yogyakarta: CAPS.

Enung Nurhasanah. (2021). Pengembangan Multimedia Pembelajaran Sejarah Perkembangan Islam Berbasis Macromedia Flash untuk Meningkatkan Hasil Belajar Mahasiswa. Ainara Journal Jurnal Penelitian Dan PKM Bidang Ilmu Pendidikan),2(3), 148-153. Retrieved from http://journal.ainarapress.org/index.php/ainj/article/view/69

Fakih, Mansour. 2006. Metode Kualitatif dan Kuantitatif, Yogyakarta: Graha Ilmu.

Fathirma'ruf. (2021). Pengembangan Game Edukasi Berbasis Flash Sebagai Sarana Belajar Siswa PAUD. Ainara Journal (Jurnal Penelitian Dan PKM Bidang Ilmu Pendidikan), 2(3), 143-147. Retrieved from http://journal.ainarapress.org/index.php/ainj/article/view/68

Friendrich Engels, 1844. Kritik Terhadap Hegelian Muda dan Trend Pemikiran Mereka. Pustaka Belajar. Gegne (dalam Pribadi, 2009:9)

Jassin, H.B. 1991. Tifa Penyair dan Daerahnya. Jakarta: Gunung Agung.

Juliet Mintchell, 1984. Pasang Surut Gerakan Feminisme. Pustaka Belajar.

Kokasih, E. 2012. Dasar-dasar KeterampilanBersastra. Bandung: Yrama Widya.

Kutha Ratna, Nyoman, Prof. S.U. 2004. Teori, Metode, dan Teknik Penelitian Sastra. Yogyakarta: Pustaka Belajar. Lubis (dalam Tarigan 1989:177).

Nurgiyantoro, Burhan. 2005. Teori Pengkajian Fiksi. Yogyakarta : Gadjah Mada University Press.

Nurgiyantoro, Burhan. 2007. Teori Penggkajian Fiksi. Yogyakarta: Gadjah Mada University Press.

Poerwadarminta, W.J.S. 1976. Kamus umum bahasa Indonesia. Jakarta: Balai Pustaka.

Rampan, Korrie. Layun. 1995. Dasar-Dasar Penulisan Cerita Pendek. Flores:Nusa Indah.

Ratna, N. K. 2007. Teori Metode, dan Teknik Penelitian Sastra. Yogyakarta: Pustaka Belajar.

Setiyono, J. 2014. Kajian Feminisme dalam Cerpen Lelaki ke-1000 di ranjangku Karya Emha Ainun Najib. Jurnal Edutama, 2(1), 14-20.

Stanton, Robert. 2007. Teori Fiksi. Terjemahan dari An Introduction to fiction. Oleh Sugihastuti dan Rossi Abi AL-Irsyad. Yogyakarta: Pustaka Belajar.

Sugihastuti, Suharto. 2005. Kritik Sastra Feminis: Teori dan Aplikasinya. Yogyakarta: Pustaka Belajar.

Sugihastuti. 2002. Teori dan Apresiasi Sastra. Yogyakarta : Pustaka Belajar. 